

\section{AMPLITUDE CALIBRATOR FOR OSCILLOSCOPES}

James R. Andrews

Eugene E. Baldwin

Electromagnetic Technology Division National Engineering Laboratory

National Bureau of Standards

Boulder, Colorado 80303

April 1981

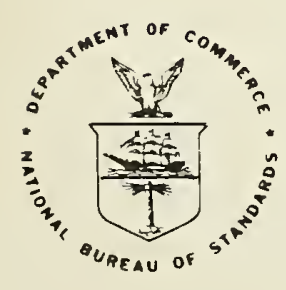

U.S. DEPARTMENT OF COMMERCE, Malcolm Baldrige, Secretary 



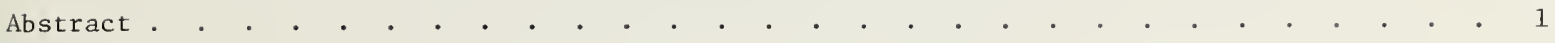

1. Introduction.

2. Specifications and Features.

3. Circuit Description and Schematics . . . . . . . . . . . . . . . . . . . . 2

4. Parts List . . . . . . . . . . . . . . . . . . . . . . . . . 10

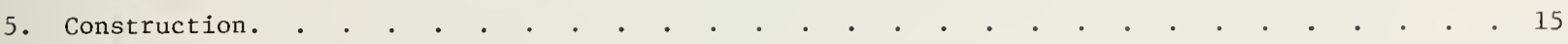

6. Alignment Procedure . . . . . . . . . . . . . . . . . . . . . . . . . 21

7. Performance Check and Calibration . . . . . . . . . . . . . . . . . . . 23

DISCLAIMER: Certain commercial equipment, instruments, or materials are identified in order to adequately specify the experimental procedure. Such identification does not imply recommendation or endorsement by the National Bureau of Standards, nor does it imply that the materials or equipment identified are necessarily the best available for the purpose. 
Figure 1.

Figure 2.

Figure 3.

Figure 4.

Figure 5.

Figure 6.

Figure 7 .

Figure 8.

Figure 9.

Figure 10.

Figure 11.

Figure 12.

Figure 13.

Figure 14.
NBS amplitude calibrator

Block diagram of amplitude calibrator. Schematic (1 of 4)

Schematic (2 of 4)

Schematic (3 of 4)

Schematic ( 4 of 4 )

Photo of assembled instrument (cover plates removed)

Rear view. (Partially disassembled)

P.C. Board 非1.

P.C. Board 非 2 .

P.C. Board 非 3 .

P.C. Board 非1 art work.

P.C. Board 非2 art work.

P.C. Board 非 3 art work.
16 
National Bureau of Standards

Boulder, Colorado 80303

The amplitude calibrator is designed to provide known dc voltage levels or $1 \mathrm{kHz}$ square waves from $\pm 1 \mathrm{mV}$ to $\pm 5 \mathrm{~V}$. It features selectable output impedances of $<0.1 \Omega$, $50 \Omega$, and $1 \mathrm{M} \Omega$. The instrument is designed with sufficient current capability to deliver its indicated voltage into a 50 termination. To protect delicate sampling oscilloscopes, a limiter circuit can also be activated to limit the output voltage to $\pm 1.8 \mathrm{~V}$.

Key words: Calibration; calibrators; instrumentation; oscilloscope calibrator; oscilloscopes

\section{Introduction}

This report describes equipment developed by NBS for calibration of the vertical axis of an oscilloscope. The amplitude calibrator (fig. I) provides voltages from $\pm I \mathrm{mV}$ to $\pm 5 \mathrm{~V}$ with $\Delta \mathrm{V}$ steps of $1 \mathrm{mV}$ to $500 \mathrm{mV}$ in a $1,2,5$ sequence and a 0 to 10 multiplier in unit steps with a source impedance of $<0.1 \Omega, 50 \Omega$, or $1 \mathrm{M} \Omega$. It produces either dc or a $1 \mathrm{kHz}$ square wave.

This report describes in detail the circuit design. Schematic diagrams, parts list, and p.c. artwork are included. A complete alignment and calibration procedure is provided.

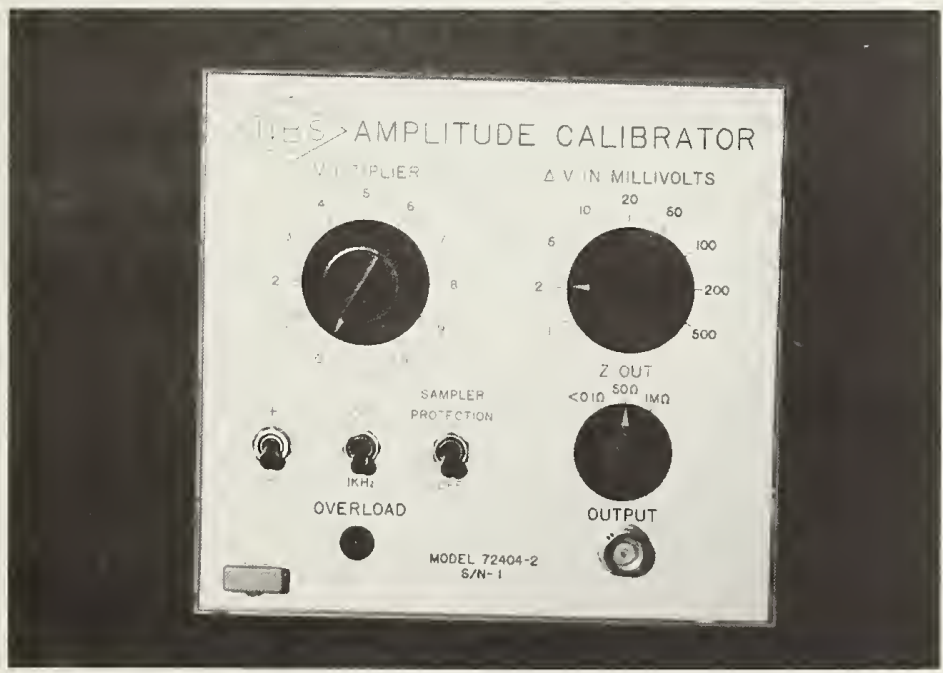

Figure 1. NBS amplitude calibrator. 


\section{Specifications and Features}

NBS Amplitude Calibrator Model - 72404-2

I. Output voltages:

a. $\pm 1 \mathrm{mV}$ to $\pm 5 \mathrm{~V}$

b. $\Delta V$ steps $-1 \mathrm{mV}$ to $500 \mathrm{mV}$ in a $1,2,5$ sequence.

c. multiplier - 0 to 10 in unit steps.

d. open circuit output voltage is $2 \mathrm{X}$ the indicated value when the output impedance switch is in the $50 \Omega$ or $I M \Omega$ positions.

II. Voltage accuracy: within $\pm 0.25 \%$ (typically $<0.1 \%$ ) except $\pm 0.4 \%$ at $2 \mathrm{mV}$ and $\pm 0.7 \%$ at $1 \mathrm{mV}$.

III. Output impedance: adjustable with 3 position switch to (a) $<0.1 \Omega,(\mathrm{b}) 50 \Omega, \pm 0.1 \%$ and (c) $1.0 \mathrm{M} \Omega, \pm 0.1 \%$.

IV. Operating modes: (a) DC or (b) $1 \mathrm{kHz}$ square wave. Square wave baseline is 0 volts. Frequency accuracy is $\pm 0.01 \%$.

V. Sampler protection: switch selectable internal circuit limits output voltage to a maximum of \pm 1.8 volts nominal.

VI. Overload protection: overload lamp lights if output current exceeds $\pm 225 \mathrm{~mA}$, nominal, and the maximum output current is limited to $\pm 275 \mathrm{~mA}$. The lamp also lights if the multiplier and $\Delta \mathrm{V}$ switches would create an output in excess of \pm 1.2 volts when the sampler protection circuit is on.

VII. Output connector: BNC

VIII. Controls: (a) $\Delta \mathrm{V}$ in $\mathrm{mV}$, (b) multiplier, (c) polarity (+ or -), (d) mode (dc or $1 \mathrm{kHz}$ ), (e) sampler protection (on or off) and (f) output impedance.

IX. Construction: the unit is a double-wide, plug-in module designed to be operated in a Tektronix TM-500 mainframe.

\section{Circuit Description and Schematics}

The block diagram of the amplitude calibrator is shown in figure 2. Detailed schematic diagrams are found in figures 3 through 7 .

The internal voltage standard for the unit is $\pm 10.000 \mathrm{~V}$ found at TP7. An LM399H, IC-10, is used as a precision voltage reference. It is a temperature stabilized, active reference zener. It features a typical temperature coefficient of $0.00003 \% /{ }^{\circ} \mathrm{C}\left(0.0002 \% /{ }^{\circ} \mathrm{C}\right.$ max.). The actual reference voltage is a nominal $6.95 \mathrm{~V}( \pm 0.35 \mathrm{~V})$. The $\pm 10.000 \mathrm{~V}$ internal standard voltage is obtained from the $6.95 \mathrm{~V}$ reference using the $I C-1$ and the resistors $R_{a}, R_{b}$, and $R_{c}$. The reference voltage is very stable with time and temperature but it is not well known (i.e., large variation in actual voltage from one unit to the next.) Thus it is necessary to provide a means of varying the gain of IC- 1 to accurately set the internal standard at precisely $\pm 10.000 \mathrm{~V}$. Resistor $\mathrm{R}_{\mathrm{c}}$ is used for this function.

Switch S1 provides the polarity function by alternately grounding either the positive or negative terminal of the $6.95 \mathrm{~V}$ rseference. The $1 \mathrm{kHz}$ square wave function is obtained using the integrated analog switch, IC-4. It grounds at a $1 \mathrm{kHz}$ rate the center point of resistors $R_{a}$ and $R_{b}$, thus forcing the input to IC-1 to zero. As a result the voltage at TP7 switches from $\pm 10.000 \mathrm{~V}$ to $0.00 \mathrm{~V}$.

The $\Delta \mathrm{i}$ function ( $1 \mathrm{mV}$ to $500 \mathrm{mV}$ in a 1-2-5 sequence) is providec by the variable gain amplifier used as an active attenuator IC-2. The gain of this stage is set by the input and feedback resistor ratio

$$
V(T P 8)=V(T P 7) \times R_{e} / R_{d} \text {. }
$$


Resistors $\mathrm{R}_{\mathrm{e}}$ and $\mathrm{R}_{\mathrm{d}}$ are precision, $0.1 \%$, resistors and are switched by a common switch to give TP8 voltages ranging from $+10 \mathrm{mV}$ to $+5.000 \mathrm{~V}$.

Following IC-2 is the multiplier attenuator, $R_{f}$. This is a passive voltage divider made up of ten, $1 \mathrm{k} \Omega, 0.1 \%$ resistors. This provides the unit step multiplier function $(0,1,2$, etc.

up to 10). To avoid upsetting the accuracy of $R_{f}$ it is followed by a very high input impedance voltage follower, IC-3.

Also following the multiplier attenuator is the sampler protection circuit. Most sampling oscilloscopes have a dynamic range of $\pm 1 \mathrm{~V}$ and burnout limits of $\pm 3 \mathrm{~V}$. Thus the maximum output from this amplitude calibrator could easily destroy a sampling oscilloscope input circuit. To protect against this a limiter circuit can be switched in to 1 imit the output voltage to a nominal $\pm 1.5 \mathrm{~V}$.

The next circuit is a hybrid power amplifier consisting of IC-3 and complementary NPN-PNP Darlington amplifier pairs. This power amplifier is capable of delivering up to $\pm 10 \mathrm{~V}$ at $200 \mathrm{~mA}$. The voltage gain of this stage is unity. The circuit includes short circuit protection.

Beyond the power amplifier is an additional switch to determine the output impedance. The output impedance of the power amplifier is typically $0.1 \Omega$. Higher impedances are obtained by inserting a series $50 \Omega$ or $1 \mathrm{M} \Omega$ resistor. The output voltage in the $50 \Omega$ and $1 \mathrm{M} \Omega$ position is calibrated in terms of the voltage delivered to a load resistance matched to the source resistance. Thus it is necessary to double the open circuit source voltage. For example when the $\Delta V$ is $500 \mathrm{mV}$, the multiplier is 10 and the $Z$ Out is $50 \Omega$ or $1 \mathrm{M} \Omega$, then the open circuit output voltage is $\pm 10.000 \mathrm{~V}$ instead of $\pm 5.000 \mathrm{~V}$. This is accomplished by an additional switch section of the $Z$ Out switch changing resistor $\mathrm{R}_{\mathrm{d}}$ in the $\Delta \mathrm{V}$ active attenuator.

The calibrator also includes an overload lamp. It lights whenever there is an overload or fault condition such as a short circuit on the output. It also lights if the sampler protection circuit is enabled and an output voltage is selected which exceeds the limiter voltage. The remainder of this section deals with particular comments related to the actual circuits.

In the $\pm 10 \mathrm{~V}$ standard circuit, IC-1, in figure 3 , the resistors $\mathrm{R}_{\mathrm{a}}$ and $\mathrm{R}_{\mathrm{b}}$ and the switch $I C-4$ are actually five resistors and four CMOS switches. Each CMOS switch has a finite on resistance of the order of $100 \Omega$. A single section switch will not give a perfect $0 \mathrm{~V}$ input to IC-1. It was necessary to use multiple sections as a ladder attenuator to achieve the desired accuracy.

The $1 \mathrm{kHz}$ square wave drive signal for IC-4 is derived from a $1 \mathrm{MHz}$ crystal oscillator, IC-5a, and three $\div 10$ dividers, IC-6, 7 and 8 . IC -9 is an additiona $1 \div 10$ which provides a 100 Hz drive signal for the external, companion, plug-in, mercury switch pulse generator.

The active $\Delta V$ attenuator, $I C-2$, is seen to have nine (R33-R41) additional resistors in the + input. These are chosen to approximate the parallel combination of $\mathrm{Rd}$ and Re to provide offset current compensation for IC-2. Likewise the extra resistors (R54-R65) in the multiplier attenuator, figure 4, provide the same function for IC-3 in conjunction with R66.

The sampler protection limiter consists of diodes CR1 and 2 and transistors Q1-Q4. The forward diode drops of CR1, Q1 and Q2 in series provide the equivalent of a $+1.5 \mathrm{~V}$ clamp. Diode CR2, Q3, and Q4 provide the same function for negative voltages. The transitors are connected as high $\beta$ Darlington amplifiers. When they start to conduct they turn on Q14 which in turn lights the overload 1amp. 
The power amplifier is also shown in figure 4. IC-3 provides a high impedance load for the multiplier attenuator and also drives the output power transistors, Q5-08. To avoid "cross-over" distortion and non-1inearities at low output levels the bias is arranged such that the output transistors are always conducting. The bias network is made up of diodes CR3-CR6 and resistors R69, 70, 71, 73, and R5. The diodes provide temperature compensation for the temperature characteristic of the transistors' base-emitter junction voltage. The JFET transistors Q15a and b are used as constant current sources to force the output transistors to always conduct a few mA of current. The actual idling current can be adjusted with R5. The actual output current is monitored by sensing the voltage drop across the $3.3 \Omega$ resistors, $R 72$ and $R 74$. If the current exceeds $250 \mathrm{~mA}$, then the voltage drop is sufficient to turn on transistor Q9 (or Q10) which in turn kills the base drive at Q5 (or Q7) and very effectively limits the output current. At a slightly lower current of $225 \mathrm{~mA}$, Q11 (or Q12) starts to conduct which in turn turns on Q13 and Q14 thereby 1ighting the overload lamp.

Each op-amp in the calibrator is equipped with a null adjustment pot. It is quite important, especially for the $\mathrm{mV}$ output levels, that each op-amp be precisely nulled to $0 \mathrm{~V}$. To facilitate these adjustments, slide switches have been provided on the circuit boards.

It is important that the spurious noise output of this calibrator be kept to an absolute minimum. The major internal source of EMI is the $1 \mathrm{MHz}$ crystal oscillator and the divider chain. To insure a quiet output signal, line filters consisting of C12, C13, C16, C19, R65 and C20 are used. The power supply lines on each card are filtered with tantalum and ceramic capacitors and RF chokes are used in the wiring between cards. In addition RC filters are used in the V+ and V- lines for each op-amp.

Figure 5 shows the wiring between the various pc cards and the front panel controls. Figure 6 shows the power supply card. Main dc power is derived from the TM-500 main-frame through the plug-in connector. The $\pm 33.5 \mathrm{~V}$ supply is pre-regulated to $\pm 20 \mathrm{~V}$ using CR9, CR11, Q16, Q18 and power transistors in the main-frame. Integrated circuit voltage regulators, IC11 and 12, are then used to obtain the required $\pm 15 \mathrm{~V}$. These voltages are further dropped to $\pm 7.5 \mathrm{~V}$ for the CMOS ICs using CR10, CR12, Q17 and Q19. 


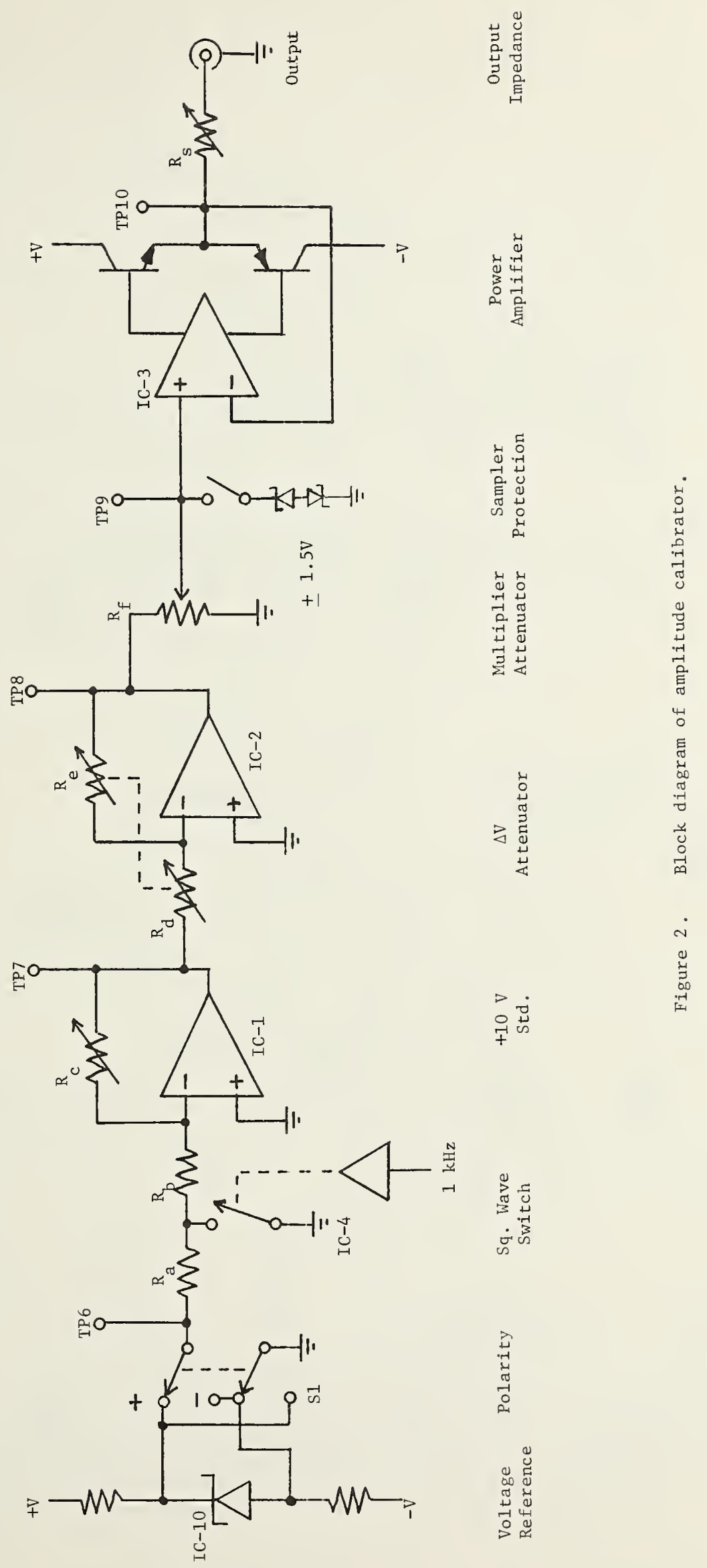




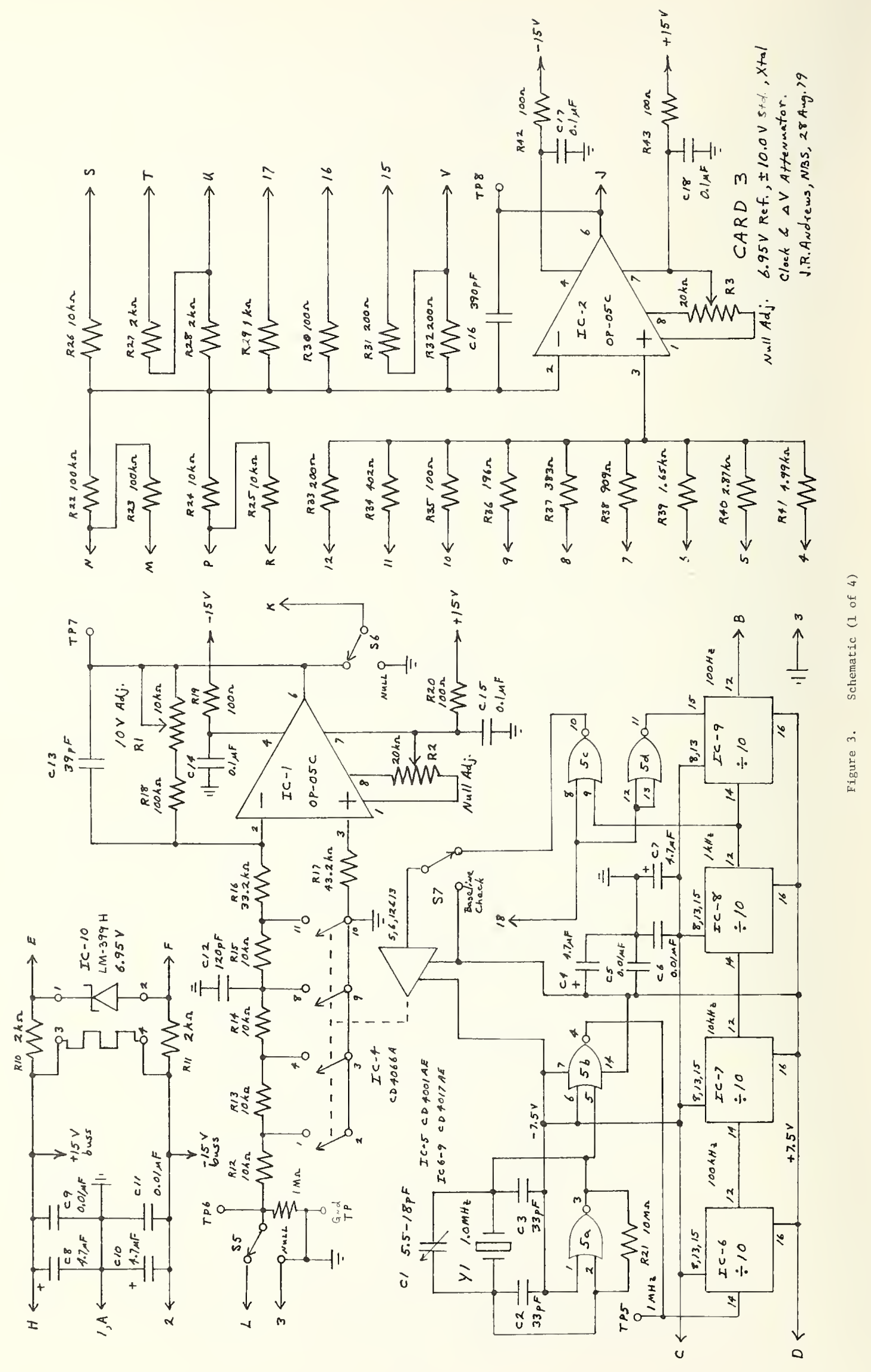



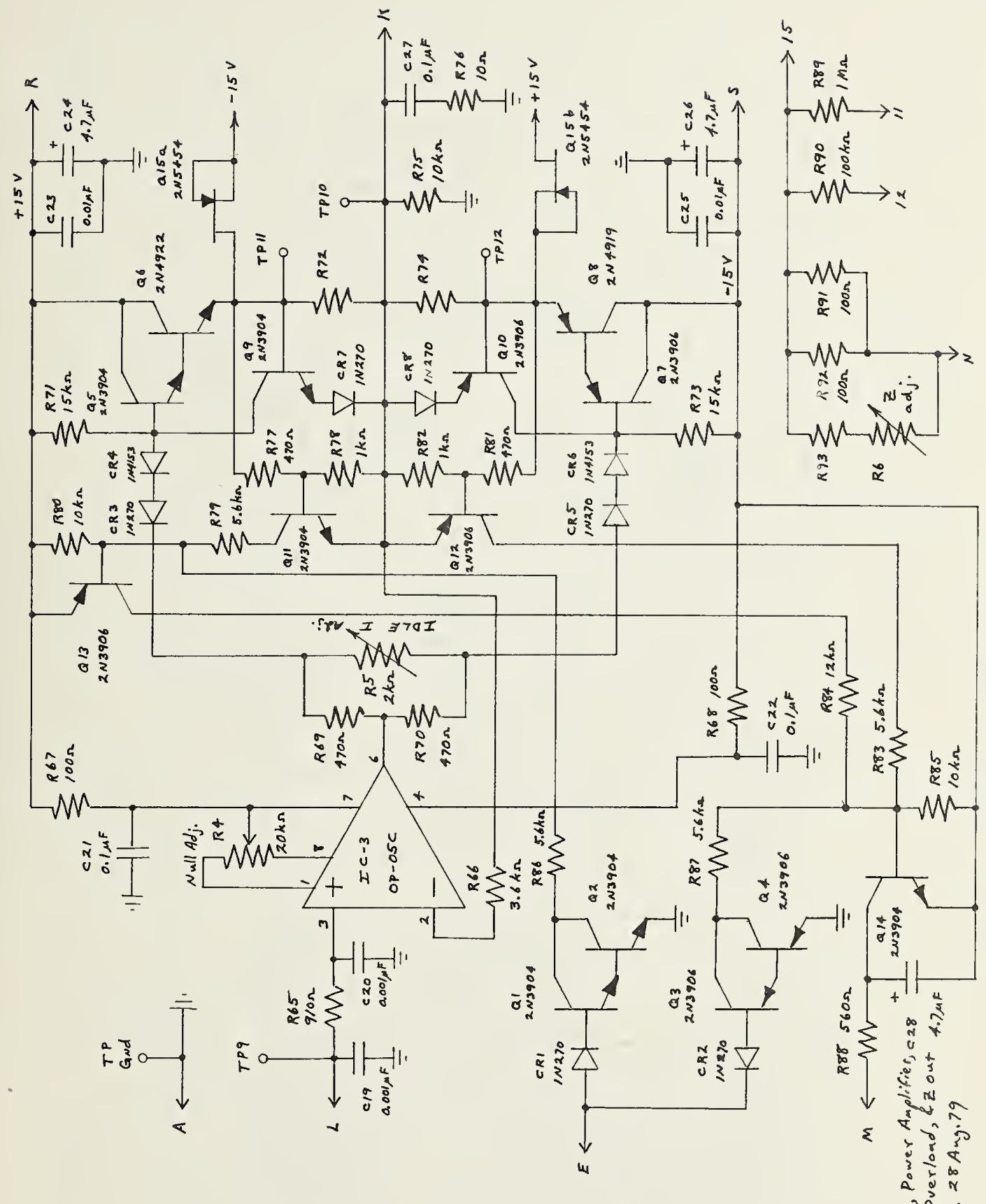

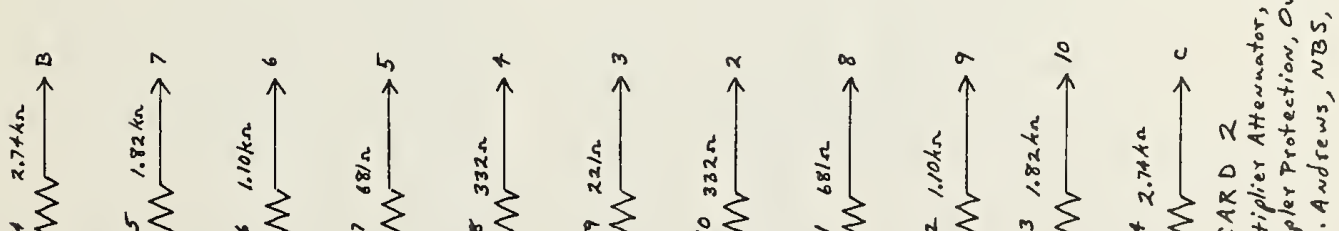
\{

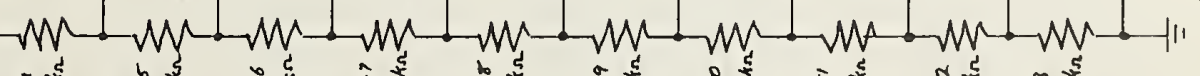

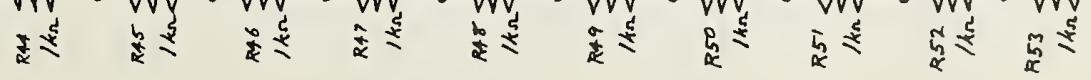




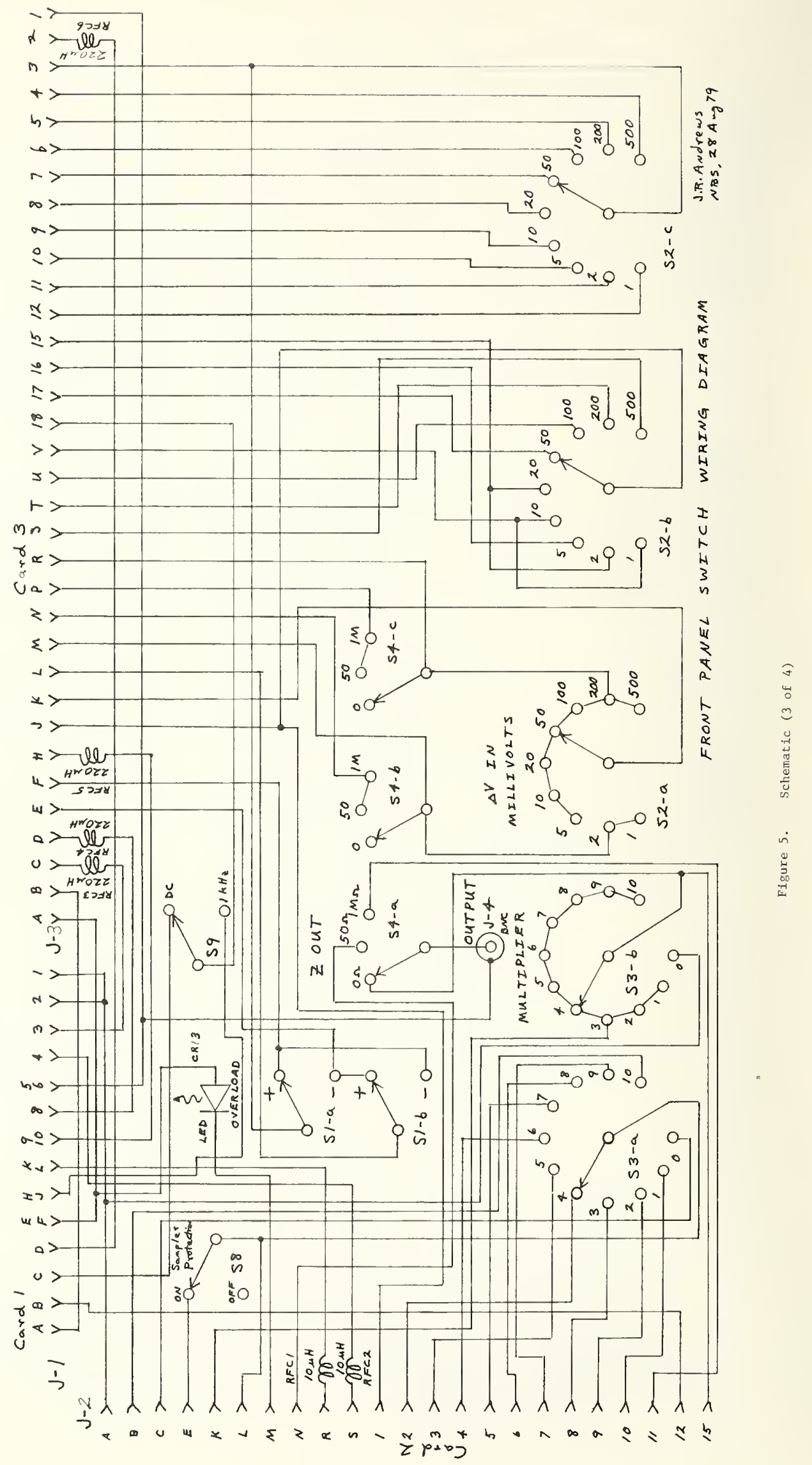




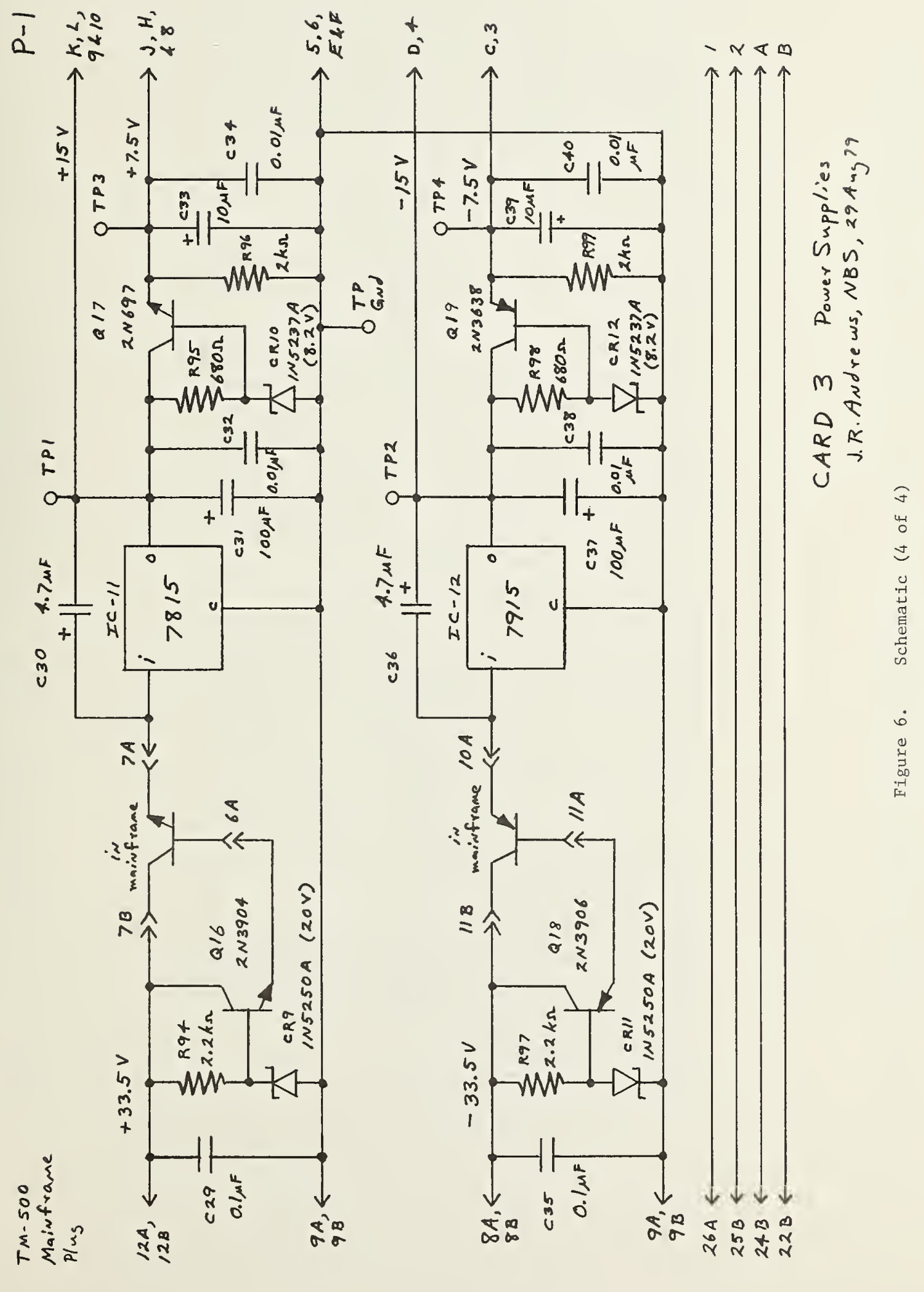


R1

R2

R3

R10

R11

$\mathrm{R} 12$

R13

R14

R1 5

R16

R17

R18

R19

R20

R21

$\mathrm{R} 22$

R23

R24

R25

R26

R27

R28

R29

R30

R31

R32

R33

R34

R35

R36

R37

R38

R39

$\mathrm{R} 40$

$\mathrm{R} 41$

R42

R4 3

R100

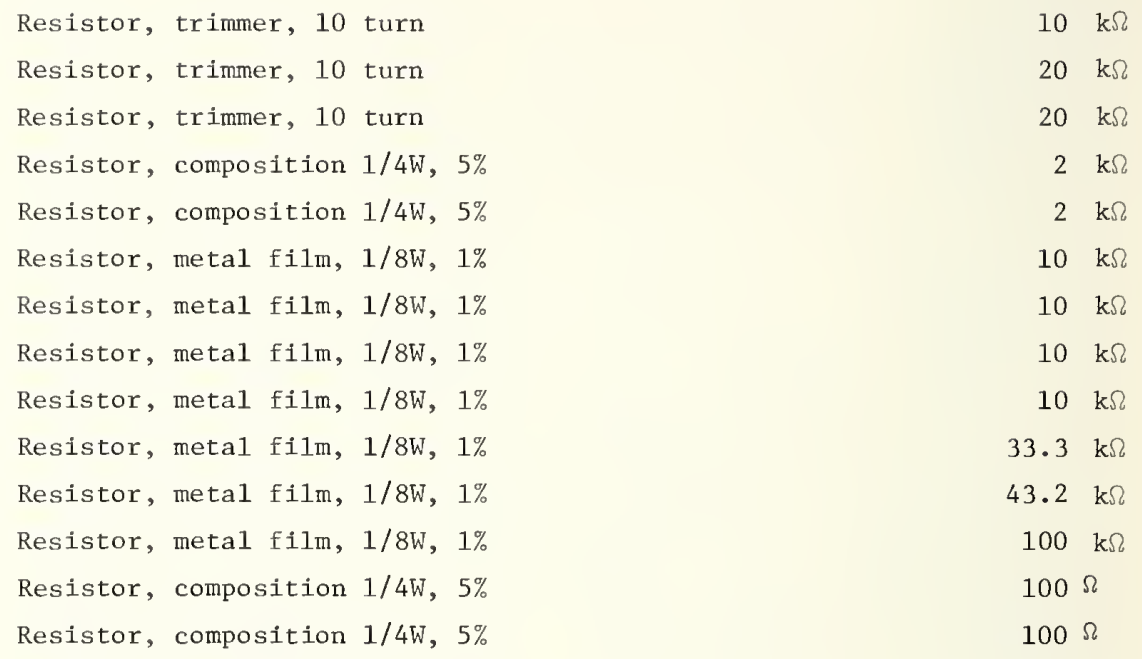

10 MEG $\Omega$ $100 \mathrm{k} \Omega$ $100 \mathrm{k} \Omega$ $10 \mathrm{k} \Omega$ $10 \mathrm{k} \Omega$ $10 \mathrm{k} \Omega$ 
C1

C2

C3

C4

C5

C6

C7

C8

C9

C10

C11

$\mathrm{C} 12$

C13

C14

C15

C16

C17

C18

Y1

ICI

IC2

IC4

IC5

IC6

IC7

IC8

IC9

IC10

S5

S6

S7
Capacitor, trimmer

Capacitor, silver mica

Capacitor, silver mica

Capacitor, tantalum

Capacitor, disc ceramic

Capacitor, disc ceramic

Capacitor, tantalum

Capacitor, tantalum

Capacitor, disc ceramic

Capacitor, tantalum

Capacitor, disc ceramic

Capacitor, silver mica

Capacitor, silver mica

Capacitor, plastic

Omitted

Omitted

Capacitor, plastic

Capacitor, plastic

Crystal, $1.0 \mathrm{MHz} ., .001 \%$

Operational amplifier

Operational amplifier

Integrated circuit, CMOS

Integrated circuit, CMOS

Integrated circuit, cMOS

Integrated circuit, CMOS

Integrated circuit, CMOS

Integrated circuit, CMOS

Integrated circuit, voltage reference

Switch, slide, miniature

Switch, slide, minlature

Switch, slide, minlature
5.5-18 pF

$33 \mathrm{pF}$

$33 \mathrm{pF}$

$4.7 \mu \mathrm{F}, 25 \mathrm{~V}$

$0.01 \mu \mathrm{F}, 50 \mathrm{~V}$

$0.01 \mu \mathrm{F}, 50 \mathrm{~V}$

$4.7 \mu \mathrm{F}, 25 \mathrm{~V}$

$4.7 \mu \mathrm{F}, 50 \mathrm{~V}$

$0.01 \mu \mathrm{F}, 50 \mathrm{~V}$

$4.7 \mu \mathrm{F}, 25 \mathrm{~V}$

$0.01 \mu \mathrm{F}, 50 \mathrm{~V}$

$120 \mathrm{pF}$

$39 \mathrm{pF}$

$0.01 \mu \mathrm{F}, 100 \mathrm{~V}$

$0.1 \mu \mathrm{F}, 100 \mathrm{~V}$

$0.1 \mu \mathrm{F}, 100 \mathrm{~V}$

OP-05C

0P-05C

CD4066A

CD4001AE

CD4017E

CD4017E

CD4017E

CD4017E

LM-399H

1 pole, 2 position

1 pole, 2 position

1 pole, 2 position 


\section{Card 2}

R44

R4 5

R46

R47

R48

R49

R50

R51

R52

R53

R54

R55

R56

R57

R58

R59

R60

R61

R62

R63

R64

R65

R66

R67

R68

R69

R70

R71

R72

R73

R74

R7 5

R76

R77

R78

R79

R80

R81

R82

R83

R84

R85

R86

R87

R88
Tesistor, Precision, 1/2 W., $0.1 \%$

$1 \mathrm{k} \Omega$

Resistor, Precision, 1/2 W., $0.1 \%$

Resistor, Precision, $1 / 2$ W., $0.1 \%$

Resistor, Precision, $1 / 2$ W., $0.1 \%$

Resistor, Precision, $1 / 2$ W., $0.1 \%$

Resistor, Precision, $1 / 2$ W., $0.1 \%$

Resistor, Precision, $1 / 2$ W., $0.1 \%$

Resistor, Precision, $1 / 2$ W., $0.1 \%$

Resistor, Precision, $1 / 2$ W., $0.1 \%$

Resistor, Precision, 1/2 W., $0.1 \%$

Resistor, Metal Film, $1 / 8$ W., $1 \%$

Resistor, Metal Film, $1 / 8$ W., $1 \%$

Resistor, Metal Film, $1 / 8$ W., $1 \%$

Resistor, Metal Film, $1 / 8$ W., $1 \%$

Resistor, Metal Film, $1 / 8$ W., $1 \%$

Resistor, Metal Film, $1 / 8$ W., $1 \%$

Resistor, Metal Film, 1/8 W., $1 \%$

Resistor, Metal Film, $1 / 8$ W., $1 \%$

Resistor, Metal Film, $1 / 8$ W., $1 \%$

Resistor, Metal Film, $1 / 8 \mathrm{~W}, 1 \%$

Resistor, Metal Film, $1 / 8$ W., $1 \%$

Resistor, Metal Film, $1 / 8$ W., $1 \%$

Resistor, Metal Film, $1 / 8$ W., $1 \%$

Resistor, Composition, $1 / 4$ W., $5 \%$

Resistor, Composition, $1 / 4$ W., $5 \%$

Resistor, Composition, 1/4 W., 5\%

Resistor, Composition, 1/4 W., 5\%

Resistor, Composition, $1 / 4$ W., $5 \%$

Resistor, Composition, $1 / 2$ W., 5\%

Resistor, Composition, 1/4 W., 5\%

Resistor, Composition, $1 / 2$ W., $5 \%$

Resistor, Composition, $1 / 4$ W., 5\%

Resistor, Composition, 1/4 W., 5\%

Resistor, Composition, $1 / 4$ W., 5\%

Resistor, Composition, 1/4 W., 5\%

Resistor, Composition, $1 / 4$ W., 5\%

Resistor, Composition, $1 / 8$ W., $5 \%$

Resistor, Composition, $1 / 4$ W., 5\%

Resistor, Composition, $1 / 4$ W., $5 \%$

Resistor, Composition, $1 / 4$ W., 5\%

Resistor, Composition, $1 / 4$ W., $5 \%$

Resistor, Composition, $1 / 8$ W., 5\%

Resistor, Composition, $1 / 4$ W., 5\%

Resistor, Composition, 1/4 W., 5\%

Resistor, Composition, 1/2 W., 5\%
$1 \mathrm{k} \Omega$

$1 \mathrm{k} \Omega$

$1 \mathrm{k} \Omega$

$1 \mathrm{k} \Omega$

$1 \mathrm{k} \Omega$

$1 \mathrm{k} \Omega$

$1 \mathrm{k} \Omega$

$1 \mathrm{k} \Omega$

$1 \mathrm{k} \Omega$

$2.74 \mathrm{k} \Omega$

$1.82 \mathrm{k} \Omega$

$1.10 \mathrm{k} \Omega$

$681 \Omega$

$332 \Omega$

$221 \Omega$

$332 \Omega$

$681 \Omega$

$1.10 \mathrm{k} \Omega$

$1.82 \mathrm{k} \Omega$

$2.74 \mathrm{k} \Omega$

$909 \Omega$

$3.57 \Omega$

$100 \Omega$

$100 \Omega$

$470 \Omega$

$470 \Omega$

$15 \mathrm{k} \Omega$

3. $3 \Omega$

$15 \mathrm{k} \Omega$

3. $3 \Omega$

$10 \mathrm{k} \Omega$

$10 \Omega$

$470 \Omega$

$1 \mathrm{k} \Omega$

$5.6 \mathrm{k} \Omega$

$10 \mathrm{k} \Omega$

$470 \Omega$

$1 \mathrm{k} \Omega$

$5.6 \mathrm{k} \Omega$

$12 \mathrm{k} \Omega$

$10 \mathrm{k} \Omega$

$5.6 \mathrm{k} \Omega$

$5.6 \mathrm{k} \Omega$

$560 \Omega$ 
Card 2

R89

R90

R91

R92

R93

R4

R5

R6

C19

C20

C21

C22

C23

C24

C25

C26

C27

C28

IC3

Q1

Q2

Q3

Q4

Q5

Q6

Q7

Q8

Q9

Q10

Q11

Q12

Q13

Q14

Q15

CR1

CR2

CR3

CR4

CR5

CR6
Resistor, Precision, $1 / 8$ W., $0.1 \%$

Resistor, Precision, $1 / 8$ W., 1\%

Resistor, Power, 3 Watt, 5\%, Selected

Resistor, Power, 3 Watt, 5\%, Selected

Selected

Resistor, Trimmer, 10 turn

Resistor, Trimmer, 10 turn

Selected

Capacitor, Disc Ceramic

Capacitor, Disc Ceramic

Capacitor, Plastic

Capacitor, Plastic

Capacitor, Disc Ceramic

Capacitor, Tantalum

Capacitor, Disc Ceramic

Capacitor, Tantalum

Capacitor, Plastic

Capacitor, Tantalum

Operational Amplifier, Precision

Transistor, Si, NPN

Transistor, Si, NPN

Transistor, Si, PNP

Transistor, Si, PNP

Transistor, Si, NPN

Transistor, Si, NPN, Power

Transistor, Si, PNP

Transistor, Si, PNP, Power

Transistor, Si, NPN

Transistor, Si, PNP

Transistor, Si, NPN

Transistor, Si, PNP

Transistor, Si, PNP

Transistor, Si, NPN

Transistor, Si, Dual J-F.E.T.

Diode, Signal, Ge

Diode, Signal, Ge

Diode, Signal, Ge

Diode, Signal, Si

Diode, Signal, Ge

Diode, Signal, Si
$1 \mathrm{M} \Omega$

$100 \mathrm{k} \Omega$

$100 \Omega$

$100 \Omega$

$20 \mathrm{~K} \Omega$

$2 \mathrm{~K} \Omega$

$0.001 \mu \mathrm{F}$

$0.001 \mu \mathrm{F}$

$0.1 \mu \mathrm{F}, 100 \mathrm{~V}$

$0.1 \mu \mathrm{F}, 100 \mathrm{~V}$

$.01 \mu \mathrm{F}, 50 \mathrm{~V}$

$4.7 \mu \mathrm{F}, 25 \mathrm{~V}$

$.01 \mu \mathrm{F}, 50 \mathrm{~V}$

$4.7 \mu \mathrm{F}, 25 \mathrm{~V}$

$0.1 \mu \mathrm{F}, 100 \mathrm{~V}$

$4.7 \mu \mathrm{F}, 25 \mathrm{~V}$

OP $-05 \mathrm{C}$

2N3904

2N3904

2N3906

2N3906

2N3904

2N4922

2N3906

2N4919

2N3904

2N3906

2N3904

2N3906

2N3906

2N3904

2N5454

1 N270

$1 \mathrm{~N} 270$

$1 \mathrm{~N} 270$

1 N4153

$1 \mathrm{~N} 270$

1 N4 153 


\section{Card 2}

CR7

CR8

\section{Card 1}

R94

R95

R96

R97

R98

R99

C29

C30

C 31

C32

C33

C34

C 35

C 36

C37

C 38

C39

C40

Q16

Q17

Q18

IC11

IC12

CR9

CR10

CR11

CR12
Diode, Signal, Ge

IN270

Diode, Signal, Ge
Resistor, Composition, $1 / 4 \mathrm{~W}, 5 \%$

Resistor, Composition, $1 / 4 \mathrm{~W}, 5 \%$

Resistor, Composition, $1 / 4 \mathrm{~W}, 5 \%$

Resistor, Composition, $1 / 4 \mathrm{~W}, 5 \%$

Resistor, Composition, $1 / 4 \mathrm{~W}, 5 \%$

Resistor, Composition, $1 / 4 \mathrm{~W}, 5 \%$

Capacitor, Disc Ceramic

Capacitor, Tantalum

Capacitor, Electrolytic

Capacitor, Disc Ceramic

Capacitor, Tantalum

Capacitor, Disc Ceramic

Capacitor, Disc Ceramic

Capacitor, Tantalum

Capacitor, Electrolytic

Capacitor, Disc Ceramic

Capacitor, Tantalum

Capacitor, Disc Ceramic

Transistor, Si, NPN

Transistor, Si, NPN

Transistor, Si, PNP

Transistor, Si, PNP

Integrated Circuit, Regulator, $+15 \mathrm{~V}$

Integrated Circuit, Regulator, $-15 \mathrm{~V}$

Diode, Zener, 20V

Diode, Zener, $8.2 \mathrm{~V}$

Diode, Zener, 20V

Diode, Zener, $8.2 \mathrm{~V}$
$2.2 \mathrm{k} \Omega$

$680 \Omega$

$2 \mathrm{~K} \Omega$

$2.2 \mathrm{~K} \Omega$

$680 \Omega$

$2 \mathrm{~K} \Omega$

$0.1 \mu \mathrm{F}, \quad 100 \mathrm{~V}$

$4.7 \mu \mathrm{F}, \quad 25 \mathrm{~V}$

$100 \mu \mathrm{F}, \quad 25 \mathrm{~V}$

$0.01 \mu \mathrm{F}, \quad 50 \mathrm{~V}$

$10 \mu \mathrm{F}, \quad 25 \mathrm{~V}$

$0.01 \mu \mathrm{F}, \quad 50 \mathrm{~V}$

$0.1 \mu \mathrm{F}, \quad 100 \mathrm{~V}$

$4.7 \mu \mathrm{F}, \quad 25 \mathrm{~V}$

$100 \mu \mathrm{F}, \quad 25 \mathrm{~V}$

$0.01 \mu \mathrm{F}, \quad 50 \mathrm{~V}$

$10 \mu \mathrm{F}, \quad 25 \mathrm{~V}$

$0.01 \mu \mathrm{F}, \quad 50 \mathrm{~V}$

2N3904

$2 \mathrm{~N} 697$

2N3906

2 N3638

7815

7915

IN5250

IN5 237

IN5250

IN5237

\section{Front Pane1}

S1

S2

S3
Switch, Toggle, 2 pole, 2 position miniature

Switch, Rotary, 3 Section, 1 Pole, 9 Position, Shorting. Centralab PSA208 or Equiv.

Switch, Rotary, 2 Section, 1 Pole, 11 Position,

Shorting, Centralab PSA204 or Equiv. 
Front Panel
L.E.D.
Diode, Light-emitting, Red
$\mathrm{J}-4$
Connector, B.N.C., Female Panel Mount
54
Switch, Rotary, Miniature, 2 Pole, 2 Position
S8
Switch, Toggle, Miniature, 1 Pole, 2 Position
S9
Switch, Toggle, Miniature, 1 Pole, 2 Position
Front Panel - special built by NBS shops per attached drawing, figure 2-7.

\section{Misce11aneous}

$$
\begin{aligned}
& \text { Blank Plug-In Kit, double wide, } \\
& \text { Connector, } 20 \text { Contact, .156" spacing } \\
& \text { or Equiv., Keyed between 2-B and 3-C } \\
& \text { Connector, } 30 \text { Contact, .156" Spacing } \\
& \text { or Equiv., Keyed between 3-C and 4-D } \\
& \text { Connector, } 36 \text { Contact, .156" Spacing } \\
& \text { or Equiv., Keyed between 1-A and 2-B. }
\end{aligned}
$$

$\begin{array}{llr}\text { RFC1 } & \text { R.F. Choke, Miniature } & 10 \mu \mathrm{H} \\ \text { RFC2 } & \text { R.F. Choke, Miniature } & 10 \mu \mathrm{H} \\ \text { RFC3 } & \text { R.F. Choke, Miniature } & 220 \mu \mathrm{H} \\ \text { RFC4 } & \text { R.F. Choke, Miniature } & 220 \mu \mathrm{H} \\ \text { RFC5 } & \text { R.F. Choke, Miniature } & 220 \mu \mathrm{H}\end{array}$

Tektronix 非040-0754-05

TRW 251-10-30-160

TRW 251-15-30-160

TRW 251-18-30-160

\section{Construction}

This instrument is designed to be operated in and powered by a Tektronix TM-500 mainframe. It is built in a double-wide, blank, plug-in kit. There are three printed circuit boards. Figures 7-11 are photographs of the assembled instrument and the separate p.c. boards. Figures $12-14$ are the art work for the p.c. boards. 


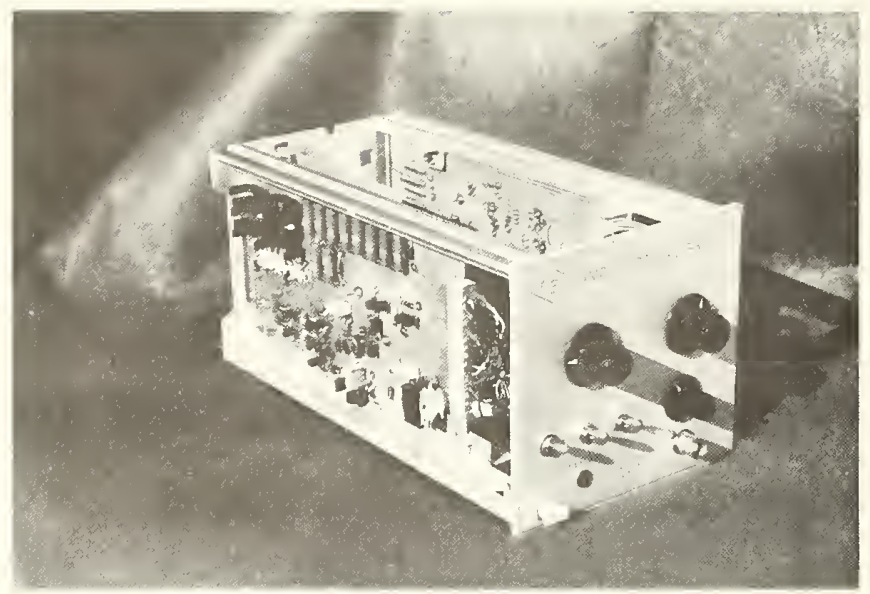

Figure 7. Photo of assembled instrument (cover plates removed).

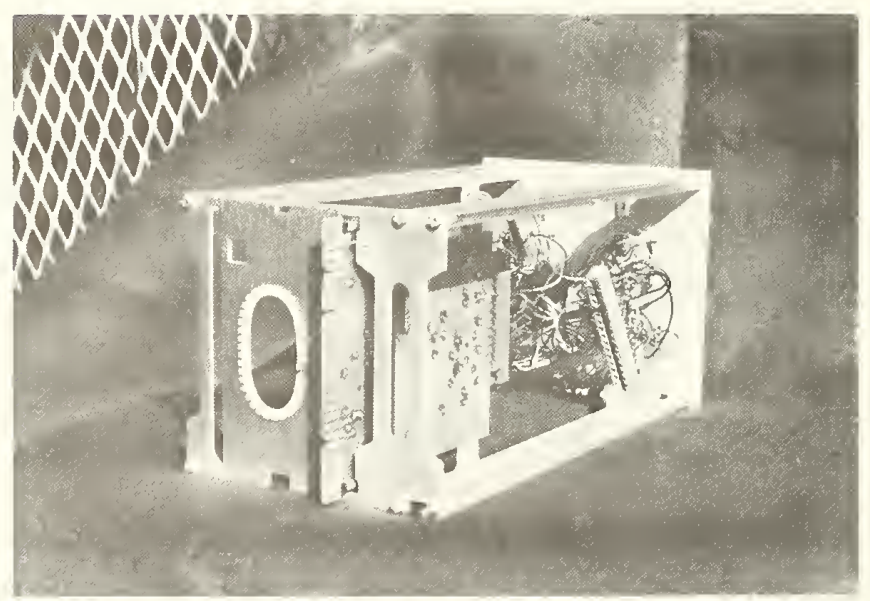

Figure 8. Rear view. (Partially disassembled) 


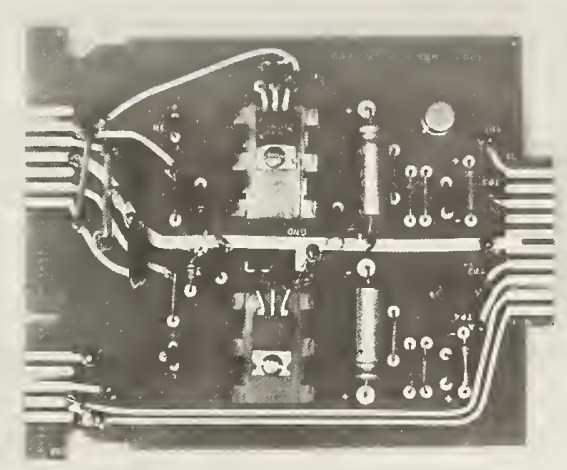

Figure 9. P.C. Board \#1.

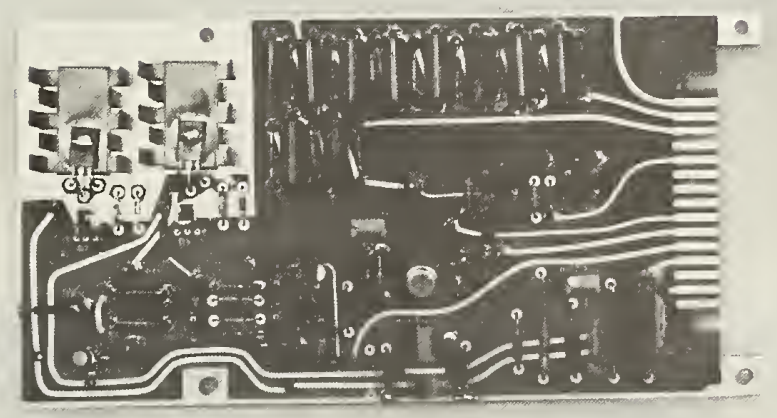

Figure 10. P.C. Board \#2.

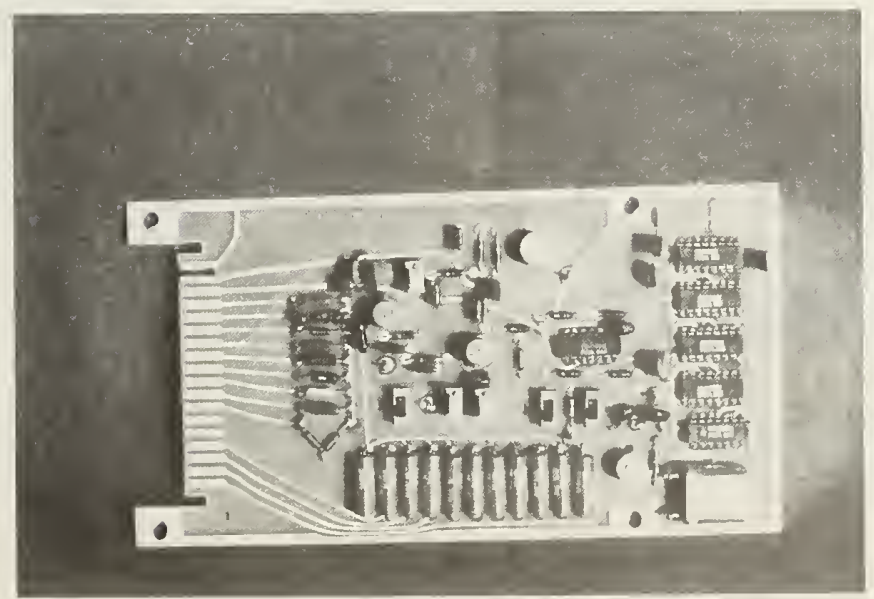

Figure 11. P.C. Board 非3. 

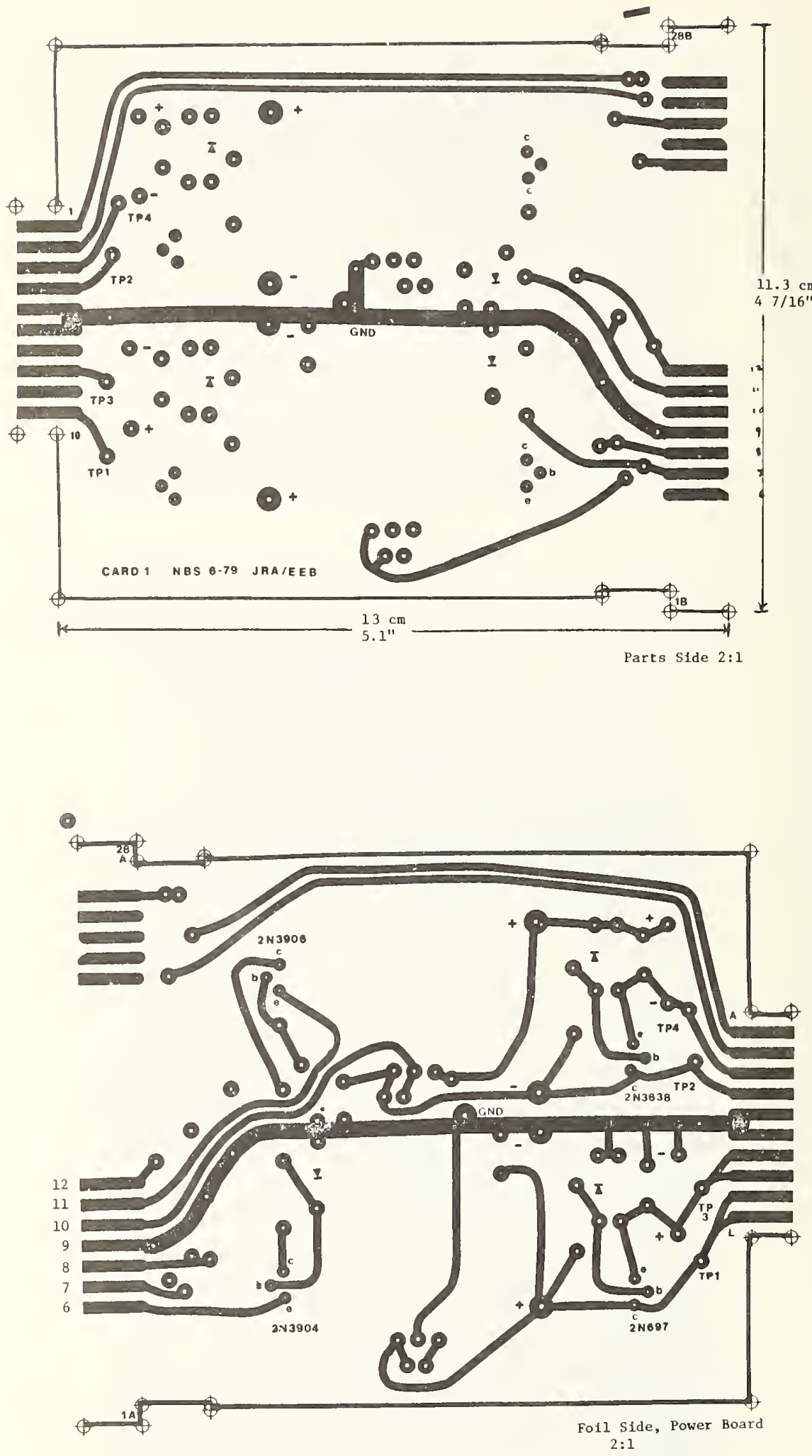

Figure 12. P.C. Board 非 1 art work. 

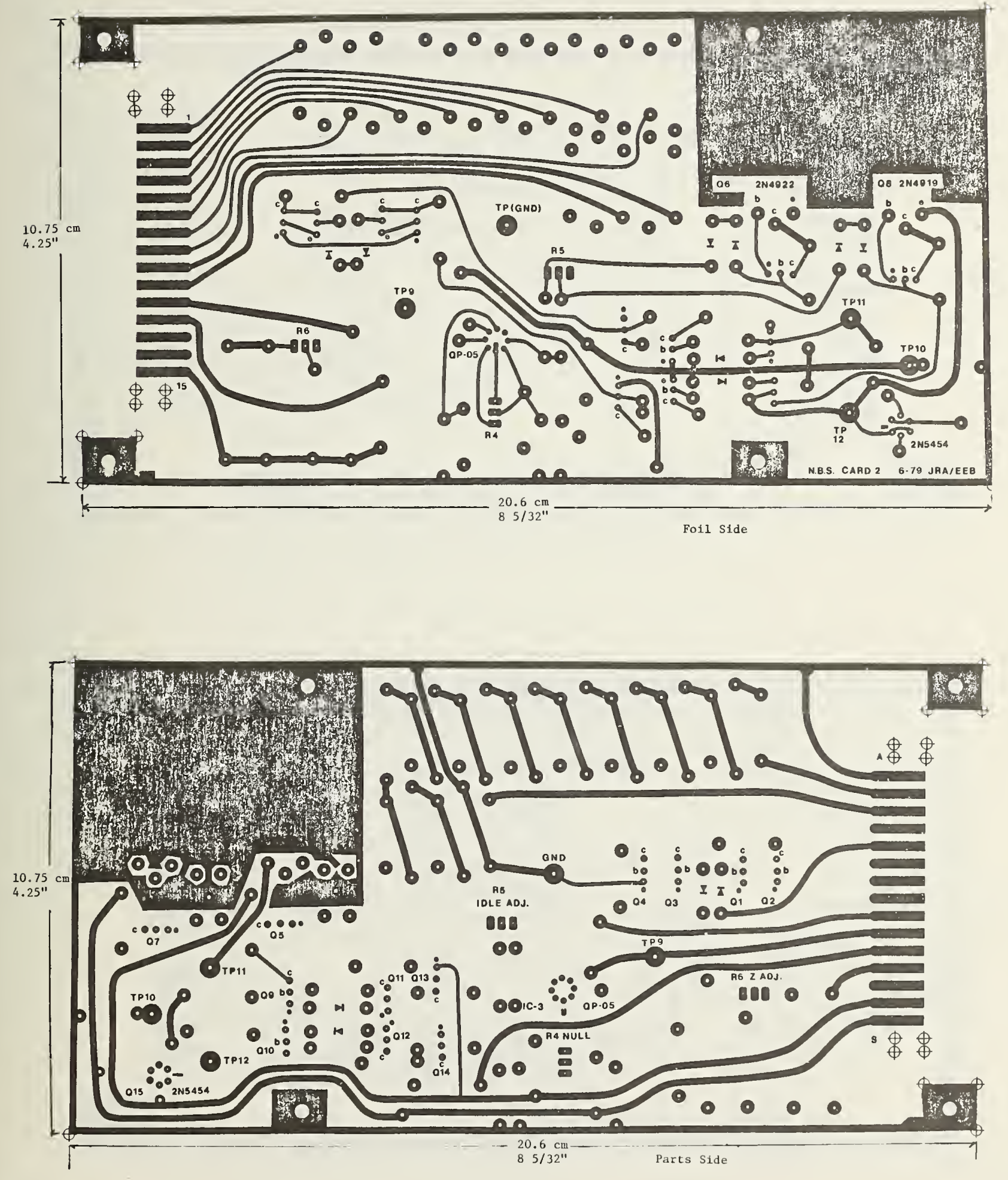

Figure 13. P.C. Board 非2 art work. 


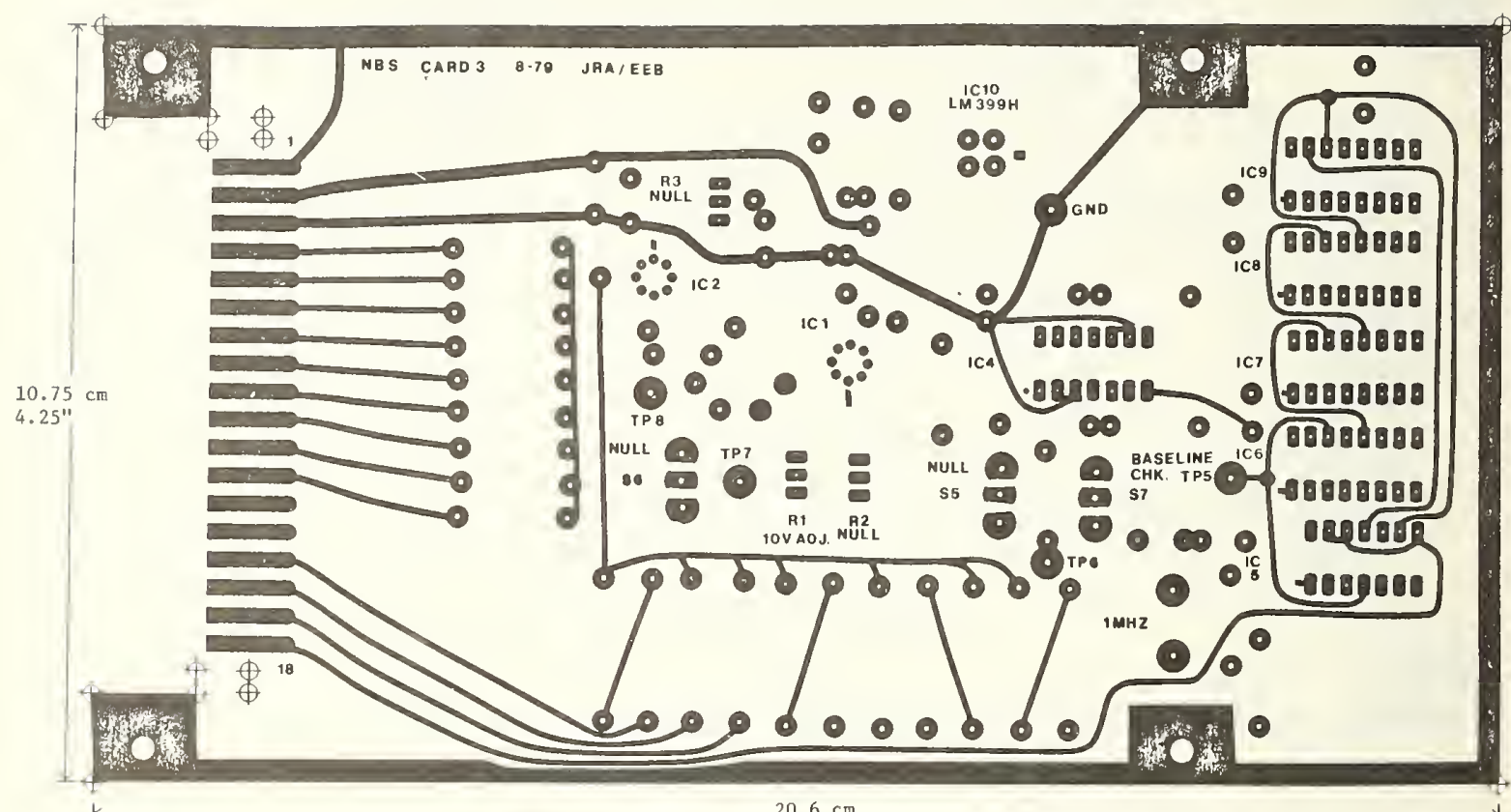

$20.6 \mathrm{~cm}$

Parts Side

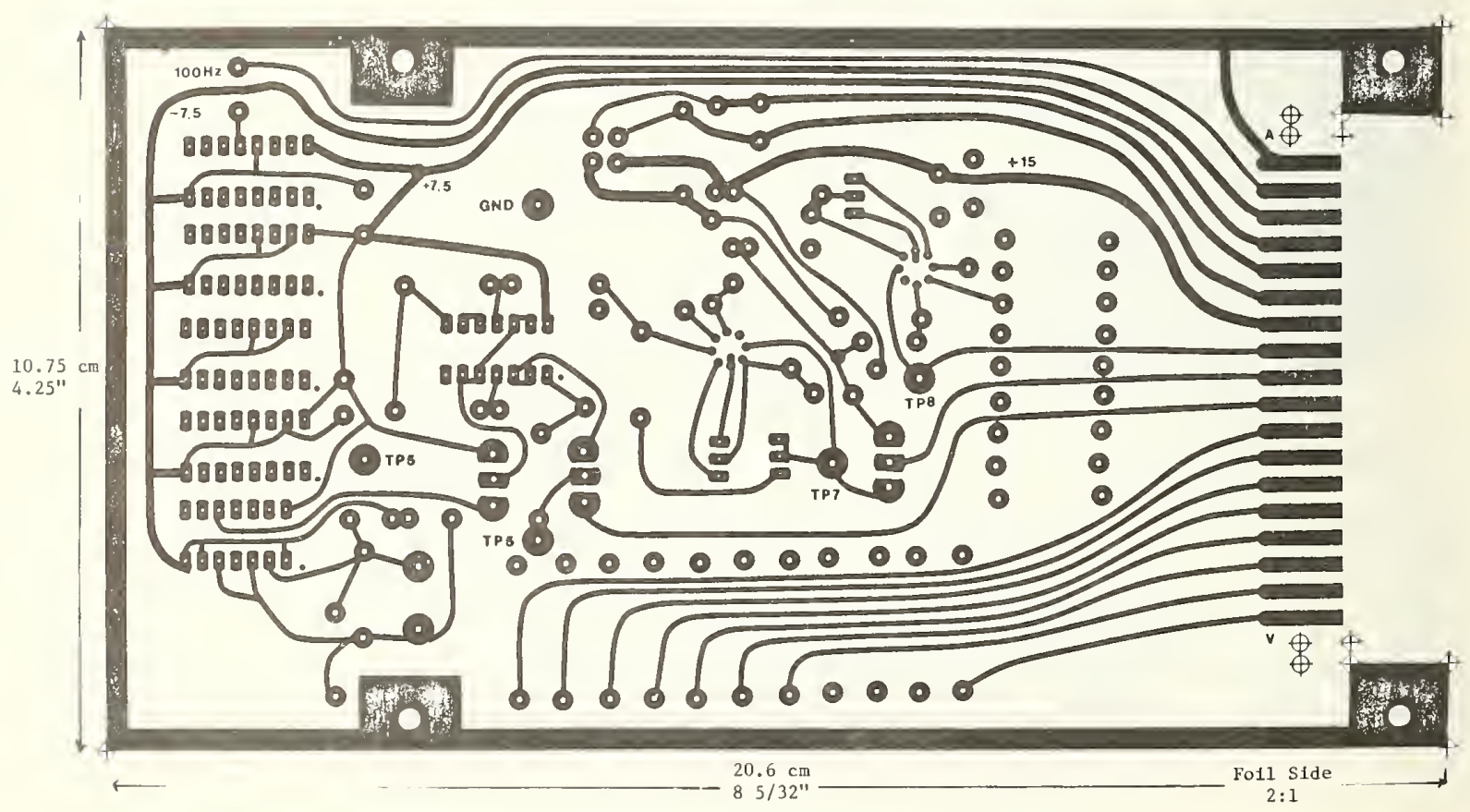

Figure 14. P.C. Board 非3 art work. 
1. Using an extender cable, install the unit in a TM 500 mainframe (power off during insertion or removal). Turn on the power. Allow 30 minutes warm-up.

2. Power Supplies:

a. Check TP1 for $+15 \mathrm{~V} \mathrm{dc}, \pm 5 \%( \pm 0.75 \mathrm{~V})$.

b. Check TP2 for $-15 \mathrm{~V}$ dc, $\pm 5 \%$.

c. Check TP3 for $+7.5 \mathrm{~V}$ dc, $\pm 5 \%$. $( \pm 0.4 \mathrm{~V})$

d. Check TP4 for $-7.5 \mathrm{~V} \mathrm{dc}, \pm 5 \%$.

3. Frequency Calibration:

a. Connect an accurate digital counter to TP5.

b. Adjust $\mathrm{Cl}$ for a frequency of $1.000 \mathrm{MHz}, \pm 0.01 \%$. $(+100 \mathrm{~Hz})$.

4. Voltage Reference:

a. Connect an accurate DVM (HP-3490 or equiv.) to TP6 (neg. lead to the ground TP).

b. Set S5 to normal.

c. Set the polarity switch, $\mathrm{S} 1$, to + .

d. TP6 voltage should read $6.95 \mathrm{~V} \pm 0.15 \mathrm{~V}$.

5. \pm 10 Volt Standard:

a. Connect the DVM to TP7.

b. Set mode switch, S9, to DC.

c. Set S5 to Null and S7 to Normal.

d. Adjust R2 for 0 volts, $\pm 5 \mu \mathrm{V}$, at TP7.

e. Set S5 to Normal.

f. Adjust $\mathrm{R} 1$ for -10.000 volts, $+2 \mathrm{mV}$, at TP7.

g. Set the polarity switch, S1, to --.

h. Check that TP7 voltage is +10.000 volts, $\pm 2 \mathrm{mV}$.

i. Set 57 to baseline check.

$j$. Check that TP7 voltage is 0 volts, $\pm 20 \mu \mathrm{V}$.

k. Repeat steps $c$ through $j$ until specs are met.

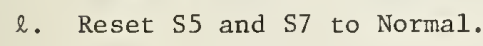

6. $\Delta \mathrm{V}$ Attenuator:

a. Connect the DVM to TP8.

b. Set S6 to Null.

c. Set the $\Delta V$ switch, $\mathrm{S} 2$, to $1 \mathrm{mV}$.

d. Set the Z Out switch, S4, to $<0.1 \Omega$.

e. Adjust R3 for TP8 voltage of $0 \mu \mathrm{V} \pm 0.5 \mu \mathrm{V}$.

f. Set S2 and S4 to all possible combinations and check that TP8 voltage remains at $0 \mu V \pm 3-7 / 3 \mu V$.

g. Reset S6 to Normal. 
7. Power Amplifier:

a. Set the multiplier switch, S3, to 0 .

b. Set the sampler protection switch, S8, to Off.

c. Connect the DVM positive lead to TP11 and the negative lead to TP12.

d. Adjust the idle current pot, $\mathrm{R} 5$, for a DVM reading of $+20 \mathrm{mV}, \pm 20 \%$.

e. Connect the DVM to TP10 (negative lead to the ground TP).

f. Adjust $\mathrm{R} 4$ for TP10 voltage of $0 \mathrm{~V}, \pm 5 \mu \mathrm{V}$.

g. Repeat steps c through f until both specs. are met.

8. Output Impedance:

a. Make up a nominal $50 \mathrm{ohm}$ load using a wire wound, $50 \Omega$ resistor of at 1 east a 20 watt rating. Solder a coaxial cable to the resistor. The other end of the coax should be terminated in a BNC plug which is connected to one arm of a BNC tee.

b. Using an accurately calibrated ohmeter, measure the actual resistance of the $50 \Omega 1$ oad as seen at the BNC tee. Record this value. ohms.

c. Using the BNC tee connect both the $50 \Omega 1$ oad and the DVM to the BNC output connector.

d. Set the $\Delta V$ switch to $500 \mathrm{mV}$, the multiplier to 10 , the Polarity to + , the mode to DC, the Sampler Protection to off, and the $\mathrm{Z}$ Out to $50 \Omega$.

e. Disconnect the $50 \Omega$ load from the BNC tee.

f. Measure and record the output voltage. Vopen ckt. $\mathrm{mV}$.

g. Compute the expected output voltage when the load is connected and the source resistance is precisely $50.00 \Omega$.

$$
\begin{aligned}
& \mathrm{V}_{\text {load }}=\mathrm{V}_{\text {open ckt }} \mathrm{R}_{\text {load }} /\left(\mathrm{R}_{\text {load }}+50.00 \Omega\right) . \\
& \mathrm{V}_{\text {load }}=\frac{\mathrm{mV} .}{\mathrm{mV}}
\end{aligned}
$$

h. Select an appropriate combination of R6 and R93 to be used and solder them to the circuit board.

i. Adjust R6 until the output voltage is precisely that calculated in step $\mathrm{g}$.

j. The output resistance is now precisely $50.00 \Omega$.

9. The alignment is now complete. 


\section{Performance Check and Calibration}

\section{Initial Set-Up}

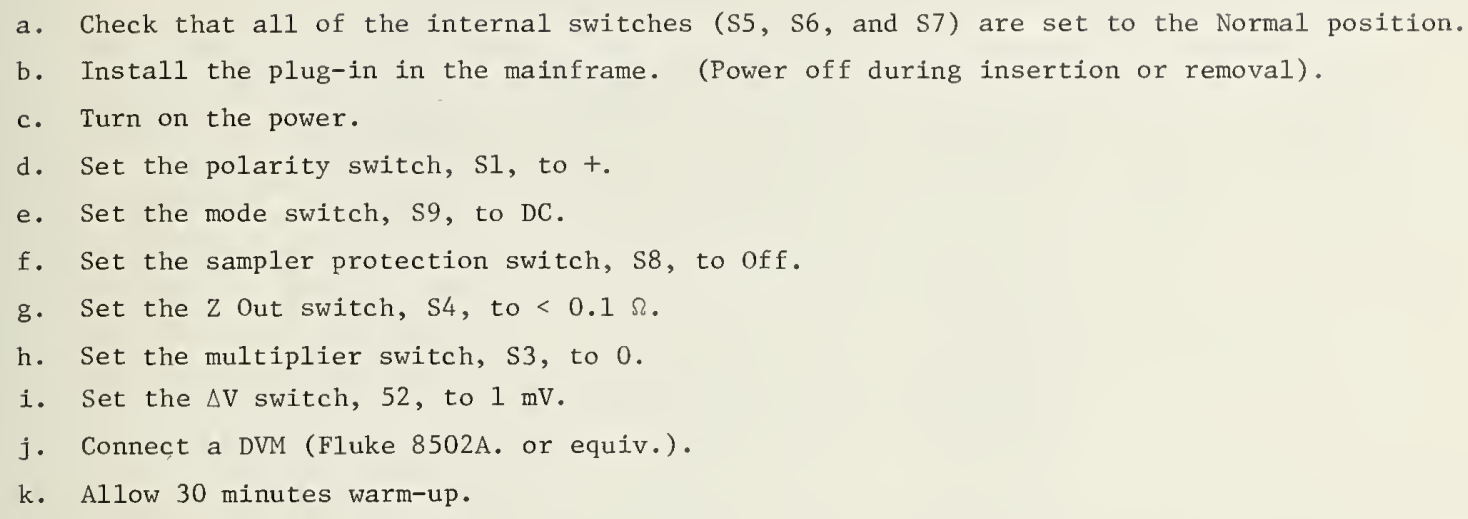

2. DVM Zero Check

Check that the DVM reads 0 volts $( \pm 1 \mu \mathrm{V})$ on all of its ranges.

3. Multiplier Attenuator Check

a. Set the DVM to the $10 \mathrm{~V}$ range.

b. Set the $\Delta \mathrm{V}$ switch, $\mathrm{S} 2$, to $500 \mathrm{mV}$.

c. Set the multiplier switch, S3, to its various positions and record the DVM readings. Change the DVM range as necessary. Compare the results to the specs. In the following table:

\begin{tabular}{ccc}
$\begin{array}{c}\text { Multiplier } \\
\text { Setting }\end{array}$ & $\begin{array}{c}\text { Output } \\
\text { Voltage }\end{array}$ & Limits \\
\cline { 1 - 2 } 1 & $0.500 \mathrm{~V}$ & $\pm 1.3 \mathrm{mV}$ \\
2 & $1.000 \mathrm{~V}$ & $\pm 2.5 \mathrm{mV}$ \\
3 & $1.500 \mathrm{~V}$ & $\pm 3.8 \mathrm{mV}$ \\
4 & $2.000 \mathrm{~V}$ & $\pm 5.0 \mathrm{mV}$ \\
5 & $2.500 \mathrm{~V}$ & $\pm 6.3 \mathrm{mV}$ \\
6 & $3.000 \mathrm{~V}$ & $\pm 7.5 \mathrm{mV}$ \\
7 & $3.500 \mathrm{~V}$ & $\pm 8.8 \mathrm{mV}$ \\
8 & $4.000 \mathrm{~V}$ & $\pm 10.0 \mathrm{mV}$ \\
9 & $4.500 \mathrm{~V}$ & $\pm 11.3 \mathrm{mV}$ \\
10 & $5.000 \mathrm{~V}$ & $\pm 12.5 \mathrm{mV}$
\end{tabular}

4. Polarity Check

a. Set the $\Delta \mathrm{V}$ switch to $500 \mathrm{mV}$.

b. Set the multiplier switch to 10 .

c. Switch the polarity switch, S1, between + and -. Record the DVM readings. They must read $\pm 5.000 \mathrm{~V}( \pm 12.5 \mathrm{mV})$. 
5. $\Delta \mathrm{V}$ Attenuator Check

a. Set the multiplier switch to 10 .

b. Set the polarity switch to + .

c. Set the $\Delta V$ switch to its various positions and record the DVM readings. Change the DVM range as necessary. Compare the results to the specs. in the following table:

$\begin{array}{cccc}\begin{array}{c}\Delta V \\ \text { Setting }\end{array} & \begin{array}{c}\text { Output } \\ \text { Voltage }\end{array} & \text { Limits } & \begin{array}{c}\text { Measured } \\ \text { Output Voltage }\end{array} \\ 500 & 5.000 \mathrm{~V} & \pm 12.5 \mathrm{mV} & \\ 200 & 2.000 \mathrm{~V} & \pm 5.0 \mathrm{mV} & \\ 100 & 1.000 \mathrm{~V} & \pm 2.5 \mathrm{mV} & - \\ 50 & 500.0 \mathrm{mV} & \pm 1.25 \mathrm{mV} & - \\ 20 & 200.0 \mathrm{mV} & \pm 500 \mu \mathrm{V} & \\ 10 & 100.0 \mathrm{mV} & \pm 250 \mu \mathrm{V} & \\ 5 & 50.0 \mathrm{mV} & \pm 125 \mu \mathrm{V} & \\ 2 & 20.00 \mathrm{mV} & \pm 50 \mu \mathrm{V} & \\ 1 & 10.00 \mathrm{mV} & \pm 25 \mu \mathrm{V} & \\ & & \end{array}$

6. Z Out Voltage Shift Check

a. Set the $\mathrm{Z}$ Out switch, S4, to $50 \Omega$.

b. Set the $\Delta V$ switch to its various positions and record the DVM readings. Change the DVM range as necessary. Compare the results to the specs. in the following table:

\begin{tabular}{ccc}
$\begin{array}{c}\Delta V \\
\text { Setting }\end{array}$ & $\begin{array}{l}\text { Output } \\
\text { Voltage }\end{array}$ & Limits \\
\cline { 2 - 3 } 500 & $10.000 \mathrm{~V}$ & \pm \\
200 & $4.000 \mathrm{~V}$ & $\pm 25 \mathrm{mV}$ \\
100 & $2.000 \mathrm{~V}$ & $\pm 10 \mathrm{mV}$ \\
50 & $1.000 \mathrm{~V}$ & $\pm 2.5 \mathrm{mV}$ \\
20 & $400.0 \mathrm{mV}$ & $\pm 1.0 \mathrm{mV}$ \\
10 & $200.0 \mathrm{mV}$ & $\pm 500 \mu \mathrm{V}$ \\
5 & $100.0 \mathrm{mV}$ & $\pm 250 \mu \mathrm{V}$ \\
2 & $40.00 \mathrm{mV}$ & $\pm 100 \mu \mathrm{V}$ \\
1 & $20.00 \mathrm{mV}$ & $\pm 50 \mu \mathrm{V}$
\end{tabular}

\section{2 Out Impedance Check}

a. Make up a nominal $50 \Omega$ load using a wire wound, $50 \Omega$ resistor of at least a 20 watt rating.

Solder a coaxial cable to the resistor. The other end of the coax should be terminated in a BNC plug which is connected to one arm of a BNC tee.

b. Using an accurately calibrated ohmmeter, measure the actual resistance of the $50 \Omega$ load as seen at the BNC tee. Record this value. $\mathrm{R}_{\text {load }}=$ ohms.

c. Using the BNC tee connect both the $50 \Omega$ load and the DVM to the BNC output connector.

d. Set the $\Delta V$, multiplier, and $Z$ Out switches as shown in the table below. Record the DVM readings with the load attached ( $\mathrm{V}_{1 \mathrm{oad}}$ ) and also with the load disconnected (V open ckt.). Compute the output resistance, $R_{\text {out }}$, using the following equation: 


$$
R_{\text {out }}=R_{\text {load }}\left(V_{\text {open ckt. }}-V_{\text {load }}\right) / V_{\text {load }} \text {. }
$$

In the $<0.1 \Omega$ position the output resistance must be no larger than $0.15 \Omega$. In the $50 \Omega$ position the output resistance must be $50.00 \Omega, \pm 0.05 \Omega$.

\begin{tabular}{|c|c|c|c|c|c|}
\hline $\begin{array}{l}\mathrm{Z} \text { Out } \\
\text { Switch }\end{array}$ & $\begin{array}{c}\Delta V \\
\text { Switch }\end{array}$ & $\begin{array}{c}\text { Multiplier } \\
\text { Switch }\end{array}$ & $\mathrm{V}_{\text {load }}$ & $\mathrm{V}_{\text {open }} \mathrm{ckt}$ & $\mathrm{R}_{\text {out }}$ \\
\hline$<0.1 \Omega$ & $500 \mathrm{mV}$ & 10 & $\mathrm{mV}$ & $\mathrm{mV}$ & $s$ \\
\hline $50 \Omega$ & $500 \mathrm{mV}$ & 10 & $\mathrm{mV}$ & $\mathrm{mV}$ & $s$ \\
\hline$<0.1 \Omega$ & $20 \mathrm{mV}$ & 9 & $\mathrm{mV}$ & $\mathrm{mV}$ & $\varsigma$ \\
\hline $50 \Omega$ & $20 \mathrm{mV}$ & 9 & $\mathrm{mV}$ & $\mathrm{mV}$ & 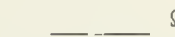 \\
\hline
\end{tabular}

e. Disconnect the BNC tee and $50 \Omega$ load from the output connector.

f. Set the multiplier switch to 0 .

g. Set the $\mathrm{Z}$ Out switch to $1 \mathrm{M} \Omega$.

h. Using the DVM as an ohmmeter, connect it to the BNC output connector and measure the resistance. Record this value. $\mathrm{R}_{\text {out }}(1 \mathrm{M} \Omega)$ ohms.

The output resistance must be $1.00 \mathrm{M} \Omega, \pm 1 \mathrm{k} \Omega$.

\section{Overload Protection Check}

a. Set the $Z$ Out switch to $<0.1 \Omega$.

b. Set the $\Delta V$ switch to $50 \mathrm{mV}$ and the multiplier switch to 0 .

c. Connect a milliampmeter (1A range) to the BNC output connector.

d. Increase the multiplier switch in steps and observe the Overload lamp. The output current threshold at which the lamp lights shall be at least $210 \mathrm{~mA}$, but less than $240 \mathrm{~mA}$.

$$
\text { Overload Lamp Threshold = }
$$
ma.

e. Set the $\Delta V$ switch to $500 \mathrm{mV}$ and the multiplier switch to 10 .

f. Measure and record the maximum output current. It shall be at least $250 \mathrm{~mA}$ but 1 ess than $300 \mathrm{~mA}$. $I_{\max }$. $\mathrm{mA}$.

g. Set the mode switch to $1 \mathrm{kHz}$ and verify that the overload lamp is on. Return the switch to DC.

h. Set the $Z$ Out switch to $50 \Omega$ and verify that the overload lamp remains off.

i. Set the polarity switch to - and repeat steps b through $h$.

j. Remove the milliammeter from the output connector.

\section{Sampler Protection Check}

a. Connect the DVM to the BNC output connector.

b. Set the polarity switch to + .

c. Set the $\Delta V$ switch to $200 \mathrm{mV}$, the multiplier to 0 and the $\mathrm{Z}$ out to $0.1 \Omega$.

d. Increase the Multiplier setting one unit at a time. Note the output voltage. Then set the Sampler Protection switch to on and note the output voltage. The protection threshold is the first level at which a difference is noted in the two DVM readings. Record this level. This threshold shall be at least $1.1 \mathrm{~V}$ but less than $1.5 \mathrm{~V}$. The Overload lamp must also light when the threshold is reached.

$$
\text { Protection Threshold = }
$$
$\mathrm{mV}$.

e. Set the $\Delta V$ switch to $500 \mathrm{mV}$, the Multiplier to 10 , and the $\mathrm{Z}$ Out to $50 \Omega$. 
f. Measure and then record the output voltage. It must be less than $2.0 \mathrm{~V}$.

Protection Threshold $\mathrm{mV}$.

g. Set the polarity switch to - and repeat steps c through $\mathrm{f}$.

0. Square Wave Operation Check

a. Set the $\Delta V$ switch to $500 \mathrm{mV}$, the Multiplier to 10 , the $\mathrm{z}$ Out to $<0.1 \Omega$, and the polarity to t.

b. Connect an oscilloscope to the output.

c. A 5 volt square wave with a baseline of 0 volts should be observed.

d. Measure and record the rising and falling transition durations ( $10 \%$ - 90\%). They must be less than $40 \mu \mathrm{s}$. The waveform must be clean with no perturbations such as overshoot or undershoot. Transition Duration $=\ldots$. $\mu$ s.

e. Remove the oscilloscope.

f. Connect a frequency counter to the output.

g. Measure and record the square wave repetition rate. It must be $1.0 \mathrm{kHz} \pm 0.01 \%$. Frequency = $\mathrm{kHz}$.

1. Noise Output Check

a. Using a BNC cable connect the output to the input of an AC VTVM (HP-400 or equiv.) through a $50 \Omega$ BNC feed-thru termination.

b. Set the $\Delta V$ to $500 \mathrm{mV}$, Multiplier to $10, \mathrm{Z}$ Out to $50 \Omega$ s, mode to $\mathrm{DC}$, and Sampler Protection to off.

c. Measure and record the ac noise voltage. It must be less than $200 \mu \mathrm{V}$ rms. Noise Voltage (high level) = $\mu \mathrm{V}$ rms.

d. Set the $\Delta V$ to $1 \mathrm{mV}$ and the Multiplier to 1 .

e. Measure and record the ac noise voltage. It must be less than $25 \mu \mathrm{V}$ rms. Noise Voltage (low leve1) = $\mu \mathrm{V}$ rms.

2. The performance check and calibration is now complete. 
NBS.114A (REV. 9-78)

\begin{tabular}{|c|c|c|c|}
\hline $\begin{array}{l}\text { - U.S. DEPT. OF COMM. } \\
\text { BIBLIOGRAPHIC DATA } \\
\text { SHEET } \\
\end{array}$ & $\begin{array}{l}\text { 1. PUBLICATION OR REPORT NO. } \\
\text { NBSIR } 87-1646\end{array}$ & 2.Gov't. Accession No. & 3. Feciptort is Accession tho \\
\hline \multirow{2}{*}{\multicolumn{3}{|c|}{$\begin{array}{l}\text { 4. TITLE AND SUBTITLE } \\
\text { Amplitude Calibrator for Oscilloscopes }\end{array}$}} & $\begin{array}{l}\text { 5. Publication Date } \\
\text { Apri } 1981\end{array}$ \\
\hline & & & 6. Performing Organization Code \\
\hline \multicolumn{3}{|c|}{$\begin{array}{l}\text { 7. AUTHOR(S) } \\
\text { James R. Andrews, Eugene E. Baldwin }\end{array}$} & 8. Performing Organ. Report No. \\
\hline \multirow{2}{*}{\multicolumn{3}{|c|}{$\begin{array}{l}\text { 9. PERFORMING ORGANIZATION NAME AND ADDRESS } \\
\text { NATIONAL BUREAU OF STANDARDS } \\
\text { DEPARTMENT OF COMMERCE } \\
\text { WASHINGTON, DC } 20234\end{array}$}} & 10. Project/Task/Work Únit No. \\
\hline & & & 11. Contract/Grant No. \\
\hline \multirow{2}{*}{\multicolumn{3}{|c|}{ 12. SPONSORING ORGANIZATION NAME AND COMPLETE ADDRESS (street, City, State, ZIP) }} & 13. Type of Report \& Period Covered \\
\hline & & & 14. Sponsoring Agency Code \\
\hline \multicolumn{4}{|c|}{$\begin{array}{l}\text { 15. SUPPLEMENTARY NOTES } \\
\square \text { Document describes a computer program; SF-185, FIPS Software Summary, is attached. }\end{array}$} \\
\hline \multicolumn{4}{|c|}{$\begin{array}{l}\text { 16. ABSTRACT (A 200-word or less tactual summaty of most signiticant information. It document includes a significant bibliography or } \\
\text { literature survey, mention it here.) } \\
\text { The amplitude calibrator is designed to provide known dc voltage levels or } 1 \mathrm{kHz} \text { square } \\
\text { waves from } \pm \mathrm{mV} \text { to } \pm 5 \mathrm{~V} \text {. It features selectable output impedances of }<0.1 \Omega, 50 \Omega \text {, } \\
\text { and } 1 \mathrm{M} \Omega \text {. The instrument is designed with sufficient current capability to deliver } \\
\text { its indicated voltage into a } 50 \Omega \text { termination. To protect delicate sampling oscillo- } \\
\text { scopes, a limiter circuit can also be activated to limit the output voltage to } \pm 1.8 \mathrm{~V} \text {. }\end{array}$} \\
\hline
\end{tabular}

17. KEY WORDS (six to twelve entries; alphabetical order; capitalize only the first letter of the first key word unless a proper name;

Calibration; calibrators; instrumentation; oscilloscope calibrator; oscilloscopes

\section{AVAILABILITY}

For Official Distribution. Do INot Release to NTIS

Order From Sup. of Doc., U.S. Government Printing Office, Wasinington, DC 20402, SD Stock No. SN003-003-

XXOrder From National Technical Information Service (NTIS), Springfield, VA, 22161

\section{Unlimited} separated by semicolons) DEPARTMENT OF COMMERCE

12. SPONSORING ORGANIZATION NAME AND COMPLETE AODRESS (Street, City, State, ZIP)
13. Type of Report \& Period Covered 


